\title{
Consumer Ambivalence toward Contraception - Towards an Integrative Framework
}

\author{
Piyush Sharma, Curtin University, Australia \\ M. Krishna Erramilli, Illinois Institute of Technology, USA \\ Cindy M.Y. Chung, PCI Consulting Group, Germany \\ Bharadhwaj Sivakumaran, Great Lakes Institute of Management, India
}

\begin{abstract}
Prior research shows that ambivalence towards pregnancy, low education and dissatisfaction with contraception lead to low or inconsistent contraceptive usage around the world, which in turn poses a serious challenge for the efforts to improve female health and well-being. In this paper, we extend this research by exploring the effect of 'consumer ambivalence towards contraception' on contraceptive usage and intentions. A clinic-intercept survey with 588 sexually active female consumers in Singapore shows that consumer attitudes toward contraception, satisfaction with their most familiar contraceptive method and their intercourse frequency have a positive effect on behavioral intentions towards contraception. Consumer ambivalence toward contraception has a negative effect on usage and intentions and it also negatively moderates the effects of attitudes, satisfaction and frequency of intercourse on usage and intentions.
\end{abstract}

Keywords: ambivalence, contraception, female healthcare, clinic-intercept, intercourse frequency 


\section{Consumer Ambivalence toward Contraception - Towards an Integrative Framework}

\section{INTRODUCTION}

Consistent contraception usage is one of the most important aspects of reproductive healthcare around the world because it contributes significantly to female health and well-being by preventing unwanted pregnancies and related health problems (Cleland et al., 2012; Darroch and Singh, 2013). Sex education in schools was expected to alleviate the problem of teenage pregnancies rampant in many developed countries and to control the population growth in lessdeveloped countries; however, the results have been mixed so far. While teenage pregnancy is a continuing social problem in developed countries such as UK and US (Martinez et al., 2011), contraceptive usage in developing countries such as China and India is still low despite growing access to contraception (Townsend et al., 2011).

Recent reports show that about 400,000 teenage girls give birth every year in the United States, the highest teen birth rate (about 7\%) in the developed world (CDCP, 2012). Alarmingly about half $(50.1 \%)$ of these teens did not use any contraception and only about one-fourth (24.2\%) used condoms; and such findings have led to fresh calls for comprehensive sex education in the United States (Stanger-Hall and Hall, 2011). In contrast, teenage birth rates in Europe continue to be relatively lower, ranging from $2 \%$ in Denmark and Germany to $6 \%$ in Sweden and UK, however it is not clear if this is due to better sex education or relatively more conservative social values (Kearney and Levine, 2012; McKay and Barrett, 2010).

Sex-education in Asia continues to be largely information-based, focusing mainly on human reproduction and anatomy with little discussion about specific sexual practices (Acharya et al., 2010). Moreover, traditional contraceptive methods such as abstinence and withdrawal remain popular in most emerging markets (Yurdakul and Vural, 2002), due to a lack of access to 
sex education and modern contraceptive methods and a combination of other socio-cultural and historical factors (Darroch et al., 2011). Therefore, the continuing social problem of teen pregnancies in the developed countries and poor reproductive health of young women in the lessdeveloped parts of the world highlight the importance of improving contraception usage.

Prior research shows that inconsistent contraceptive usage by females is an important direct cause of contraceptive failure leading to unwanted pregnancies and considerable physical and psychological discomfort (Fisher et al., 2005; Layte et al., 2007). The propensity to take contraceptive risks may be caused by many factors, including abortion history, dissatisfaction with current contraceptive method, low education, ambivalence towards pregnancy, history of contraceptive risk taking (Snell and Wooldridge, 2001) and mixed attitudes and feelings towards various contraceptive methods (Erramilli et al., 2005). However, prior research does not address the issue of ambivalence towards contraception despite growing evidence about its influence on other health-related domains such as smoking (Lipkus et al. 2001), food products (Olsen et al. 2005) and green advertising (Chang, 2011). We address this important research gap in this paper.

Recently, there is an upsurge of interest in the concept of ambivalence in consumer research (Hong and Lee, 2010; Hormes and Rozin, 2011; Penz and Hogg, 2011; Ursavas and Hesapci-Sanaktekin, 2011). Ambivalence reflects the co-existence of positive and negative evaluations of an attitude object, and it is different from 'indifference' or 'dissonance' (Nowlis et al., 2002). However, empirical findings about its impact are mixed; some show ambivalent attitudes as weak and less predictive of behavior (Conner et al., 2003) and less resistant to persuasion (Armitage and Conner, 2000); others find them to be more predictive of behavioral intentions (Jonas et al., 1997). 
In this paper, we explore the impact of consumer ambivalence towards contraception on female consumers' contraceptive usage behavior. Our results confirm that female consumers have ambivalent attitudes towards contraception, consisting of both positive (convenient, affordable, reliable and easily available) and negative (short-term side effects, long-term bad effects, embarrassment and against religion) elements. Younger, unmarried and non-Chinese female consumers show greater ambivalence towards contraception compared to older, married and Chinese female consumers respectively. Attitudes toward contraception, satisfaction with the most familiar contraceptive method and intercourse frequency have a positive effect on contraceptive usage and intentions. Finally, consumer ambivalence toward contraception has a negative effect on usage and intentions, and it also negatively moderates the effect of attitude, satisfaction and intercourse frequency.

In this paper, we first review the literature on consumer ambivalence and contraception to develop our conceptual framework and hypotheses about the influence of ambivalence on contraceptive usage behavior. We then describe our findings from a clinic-intercept survey with a multi-ethnic sample of 588 sexually active female consumers in Singapore. Next, we discuss the conceptual contribution and practical implications of our findings for female consumers and other stakeholders including male partners, family members, social welfare agencies, healthcare professionals and government bodies. Finally, we discuss some limitations of this research along with directions for future research in this area.

\section{LITERATURE REVIEW AND THEORETICAL BACKGROUND}

\section{Consumer Ambivalence - Structure and Measurement}

Prior research exploring the attitude-behavior link conceptualizes attitude as a unidimensional, unambivalent, bipolar construct; wherein individuals are expected to have a 
neutral, positive, or negative attitude toward any object or behavior (Eagly and Chaiken, 1993; Kraus, 1995). According to this view, individuals are likely to engage in behaviors toward which they have favorable attitudes and avoid those toward which they have negative attitudes. In other words, this view assumes positive attitudes to be the exact opposite of negative attitudes.

Others argue that individuals may simultaneously hold both negative and positive attitudes that may not correlate with one another (e.g., Cacioppo et al., 1997); and this notion has been conceptualized as attitudinal ambivalence (Thompson et al., 1995) or consumer ambivalence (Otnes et al., 1997). According to Thompson et al. (1995), ambivalence may originate from different types of conflicts, including cognitive ('mixed beliefs'), affective ('mixed feelings'), and cognitive-affective ('incongruent beliefs and feelings') conflict.

Otnes et al. (1997, p. 82-83) introduce consumer ambivalence as "the simultaneous or sequential experience of multiple emotional states, as a result of the interaction between internal factors and external objects, people, institutions, and/or cultural phenomena in market-oriented contexts, that can have direct and/or indirect ramifications on prepurchase, purchase or postpurchase attitudes and behavior". Otnes et al. (1997) also distinguish different types of consumer ambivalence based on their origins, namely psychological, sociological and cultural ambivalence. Psychological ambivalence is defined as the simultaneous or sequential experience of mixed emotions and it focuses on the internal feelings toward an object or person. In contrast, sociological ambivalence focuses on how external factors such as the social structure (e.g., social norms and social roles) may trigger mixed feelings. Finally, cultural ambivalence relates with the conflicting cultural values held by members of society (Otnes et al., 1997).

The traditional bi-polar attitude scales are not appropriate for measuring ambivalence because the mid-point in these scales cannot distinguish between indifference, ambiguity or 
ambivalence (Kaplan, 1972). Therefore, ambivalence is generally operationalized using either an objective or a subjective method. Researchers using the objective approach measure the positive and negative attitudes toward an attitude object and use one of the many mathematical formulae to calculate the ambivalence index (e.g., Breckler, 1994; Thompson et al., 1995). In contrast, the subjective assessment of ambivalence involves directly asking the individuals if their attitudes toward an object are one-sided or mixed (e.g., Tourangeau et al., 1989). Results from both objective and subjective measures of ambivalence correlate with each other (Riketta, 2000).

\section{Consumer Ambivalence - Antecedents}

Thompson and Zanna (1995) found a relationship between ambivalence and two personality measures, Need for Cognition (NFC) and Personal Fear of Invalidity (PFI), in their study of attitudinal ambivalence towards several social policy issues (e.g., reinstating capital punishment). They found NFC negatively and PFI positively correlated with ambivalence. Similarly, others show that individuals with higher preference for consistency (PFC) may experience greater ambivalence (Newby-Clark et al., 2002). Hence, some people may be psychologically more vulnerable to the experience of ambivalence compared to others based on personality factors; however, other factors may also affect ambivalence.

For example, interpersonal perceptions (Priester and Petty, 2001), deadline pressure (Jewell, 2003), familiarity (Brooks et al., 2003), anticipated conflict (Priester et al., 2007), personal relevance and information source (Tormala and DeSensi, 2008), source credibility and message consistency (Clarkson et al., 2008) may all directly or indirectly influence ambivalence. Recent research also explores the influence of culture on ambivalence and shows that East Asians have a greater tolerance for ambivalence compared to North Americans, and ambivalence has a positive influence on the degree of attitude change for the North Americans but not for East 
Asians (Ng et al., 2011). In addition, Park (2005) shows that individuals with interdependent self-construals reveal greater attitudinal ambivalence when the source of conflict is interpersonal than intrapersonal, whereas those with independent self-construals show the opposite pattern.

Otnes et al. (1997) identify several antecedents of consumer ambivalence, including product and retailer-specific expectations, product and task overload, role conflict with influencers, and conflicts with values and customs. However, there is a need to empirically examine how and to what extent all these antecedents may influence consumer ambivalence. Moreover, it would also be useful to study the influence of other antecedents on consumer ambivalence such as demographics, knowledge and past experience; and look beyond the affective aspect of ambivalence such as, the 'experience of multiple emotional states'.

\section{Consumer Ambivalence - Direct and Indirect Outcomes}

Early research on the impact of ambivalence showed ambivalent attitudes to be less stable over time, less predictive of behavior, more pliable, and to have less influence on information processing, compared to univalent attitudes that were either strongly positive or negative (e.g., Bargh et al., 1992; Sparks et al., 1992). However, others showed exactly the opposite results. For example, Jonas et al. (1997) uses the heuristic-systematic model (Chaiken et al., 1989) to show that ambivalence decreases the confidence in the attitudes toward behaviors involving the target object and leads to greater systematic processing of the relevant information.

Ambivalent attitudes consist of both positive and negative components, which are inconsistent with each other (Armitage and Conner, 2000) and this may lead to cognitive dissonance (Festinger, 1957), negative affect and emotional stress (Hass et al., 1992), which in turn may motivate people to resolve this inconsistency in order to reduce their ambivalence. 
Hence, there is a general consensus that ambivalent attitudes are more pliable (Maio et al., 1996), especially for high self-monitors (Cavazza and Butera, 2008).

Consumer researchers have explored the influence of attitudinal ambivalence in many behavioral domains. For example, smokers with more ambivalent attitudes towards smoking show greater desire to quit after controlling for other factors (Lipkus et al., 2001). In another study, purchase of condoms evoked a combination of negative beliefs about the lifestyle and positive beliefs about the personal confidence of the target consumer. However, specific beliefs about condoms were the best predictor of actual condom usage (Dahl et al., 2005). Similarly, ambivalence has a negative effect on satisfaction, repurchase loyalty and involvement for various food products (Olsen et al., 2005), while others use ambivalence to segment the convenience food market (Olsen et al., 2009). Ambivalence also affects the pre- and post-purchase stages of the decision process for consumer durables replacement (Roster and Richins, 2009) and moderates consumer responses to green advertising (Chang, 2011).

Prior research on the moderating influence of ambivalence on the link between attitude and behavior (or behavioral intentions) mostly shows a weaker attitude-behavior link under high ambivalence conditions (e.g., Conner et al., 2002; Moore, 1980; Sparks et al., 1992). Moore (1980) was one of the first to discover the association between ambivalent attitudes and low attitude-intention consistency, while others found low correlation between the attitudes and health behaviors for subjects with high ambivalence (Conner et al., 2003).Sparks et al. (1992) explain this effect by showing that ambivalent attitudes are based on discrepant evaluations that lead to a decrease in attitude-intention consistency. However, in contrast, Jonas et al. (1997) found a stronger attitude-intention link for attitudes with greater ambivalence. Jonas et al. (1997) explain this by arguing that ambivalence may reduce the confidence in the attitudes toward 
behaviors that involve the target attitude object, which in turn could lead to greater systematic information processing and hence, a stronger link between ambivalent attitudes and behaviors.

In view of the above mixed evidence, it is still not clear under which conditions ambivalence may moderate the attitude-behavior link. Moreover, there is little research on the interaction between ambivalence and other factors such as consumer experience, knowledge, involvement, and satisfaction (Olsen et al., 2005; Tuu and Olsen, 2010). Finally, there is no research into the influence of consumer ambivalence in contraceptive usage, despite evidence about mixed attitudes towards various contraceptive methods (Erramilli et al., 2005).

We address these research gaps by developing a conceptual framework with consumer ambivalence as a focal construct, along with attitude toward contraception, satisfaction with the most familiar contraceptive method and intercourse frequency as other independent variables. We also include demographic (e.g., age, education, income) and socio-normative (e.g., perceived influence of male partner and doctors) variables as antecedents of consumer ambivalence, and contraceptive usage and behavioral intentions as dependent variables. Finally, besides the direct effects of the four independent variables (e.g., consumer ambivalence, attitude, satisfaction and intercourse frequency) on the two dependent variables (e.g., contraceptive usage and intentions), we also test the moderating influence of ambivalence on the influence of the other three variables (e.g., attitude, satisfaction and intercourse frequency).

\section{CONCEPTUAL FRAMEWORK AND HYPOTHESES}

\section{Attitude, Satisfaction and Contraceptive Usage}

Contraceptive usage is a common practice around the world and with the advent of new methods that are safer, more user friendly and reliable than older methods, consumers have more choices today than ever before (Darroch et al., 2011). Contraceptives are broadly classified into 
reversible and irreversible methods - reversible methods include abstinence, withdrawal, rhythm, condoms, diaphragm, intra-uterine devices (IUD) and oral contraceptive (OC) pills, whereas irreversible methods include sterilization and uterus removal (Oakeley, 2004). Women seem to have more options for contraception compared to men, but they also seem to be responsible for contraception because they are the ones who get pregnant and bear most of its consequences (Brunner Huber and Ersek, 2011; Cox et al., 2010).

Prior research on female reproductive health and well-being shows that irregular contraceptive usage may lead to contraceptive failure, unwanted pregnancies, and significant physical and psychological discomfort (Fisher et al., 2005). In fact, in less-developed countries, pregnancy and childbirth may have serious consequences for the well-being and life expectancy of the women and their families (Carr et al., 2012; Cleland et al., 2012), especially if their economic or social circumstances cannot support their pregnancy and the child (Layte et al., 2007). Half the pregnancies among contraceptive users are unintended and mostly due to inconsistent or incorrect use of contraceptive methods (Frost and Darroch, 2008).

In view of the above, an understanding of the factors that contribute to inconsistent contraceptive usage can help improve contraceptive compliance and minimize the chances of unwanted pregnancies. The factors that lead to inconsistent contraceptive usage include ambivalent feelings towards parenthood (Zabin, 1999), history of contraceptive risk taking (Snell and Wooldridge, 2001), unfavorable attitude towards contraception (Brückner et al., 2004), lower education level, social class, early sexual initiation and ambivalence towards getting pregnant (Layte et al., 2007), dissatisfaction with current contraceptive method (Frost and Darroch, 2008), and frequent switching of contraceptive method (Moreau et al., 2009). 
Oddens (1999) found that satisfaction with the contraceptive methods for women follows this descending order: sterilization, oral contraceptives, IUD, natural methods and condoms. Similar results were reported by others showing high satisfaction with long-term reversible contraception methods (Peipert et al., 1998). However, more recent research shows greater levels of satisfaction with non-coital dependent methods compared to coital ones (Ersek et al., 2011) and higher sexual satisfaction among women who used dual methods (e.g., hormonal methods and condoms) (Higgins and Cooper, 2012). Based on these findings, it is likely that a positive attitude toward contraception and satisfaction with the most familiar contraceptive method may lead to greater and more consistent contraceptive usage and intentions. Hence, we hypothesize:

H1: Attitude toward contraception has a positive effect on contraceptive usage and behavioral intentions.

H2: $\quad$ Satisfaction with the most familiar contraceptive method has a positive effect on contraceptive usage and behavioral intentions.

\section{Intercourse Frequency and Contraceptive Usage}

Consumer involvement is defined as a predisposition to act in a certain manner and it represents the degree of mental and physical effort a consumer is willing to exert in any given consumption-related situation or behavior (Zaichkowsky, 1985). Prior research on involvement shows that it plays an important moderating role in the advertising effectiveness and persuasion processes (Petty et al., 1983) and also positively moderates the relationships in the valuesatisfaction-loyalty model (Chen and Tsai, 2008). However, there is mixed evidence about the moderating impact of involvement on the satisfaction-loyalty link; some show a positive moderating effect (Tuu and Olsen, 2010) but others show no such effect (Olsen, 2007). 
In the context of contraceptive usage, frequency of intercourse may reflect consumers' involvement with sexual activity. In other words, an increase in the frequency of sexual activities can be expected to increase the concerns of a consumer over the long-term physical and psychological consequences related to unwanted pregnancies, abortion, and family planning. Based on this, we argue that a higher intercourse frequency would not only directly increase contraceptive usage, but also strengthen the influence of attitude and satisfaction on contraceptive usage and intentions. Hence, the following hypotheses:

\section{H3: Intercourse frequency has a positive effect on contraceptive usage and} behavioral intentions.

H4: Intercourse frequency positively moderates the effect of attitude toward contraception on contraceptive usage and behavioral intentions.

H5: Intercourse frequency positively moderates the effect of satisfaction with the most familiar contraceptive method on contraceptive usage and behavioral intentions.

\section{Consumer Ambivalence and Contraceptive Usage}

Prior research across various behavioral domains shows that ambivalent attitudes are more pliable and easier to manipulate compared to non-ambivalent attitudes, resulting in a weaker link between attitudes and behavior (e.g., Conner et al., 2002; Moore, 1980; Sparks et al., 1992). The conceptual reason for this effect is the dependence of ambivalent attitudes on discrepant evaluations, which may lead to a reduction in the strength of attitude-intention association, as reflected in the low correlation between the attitudes and behaviors for subjects with high ambivalence across a wide range of behavioral contexts (Conner et al., 2003). Based on the above evidence, we argue that sexually active consumers (irrespective of whether they use 
any contraceptive methods or not) with ambivalent attitudes toward contraception may also show hesitation in using contraceptives and choose to adopt more traditional approaches such as abstinence, rhythm or withdrawal methods. Hence, we hypothesize:

\section{H6: Consumer ambivalence toward contraception has a negative effect on} contraceptive usage and behavioral intentions.

Prior research shows that sexually active individuals may possess ambivalent attitudes towards contraception (Erramilli et al., 2005), as reflected in unfavorable attitudes towards contraception (Brückner et al., 2004) coupled with dissatisfaction with current contraceptive method (Frost and Darroch, 2008) and frequent switching of contraceptive method (Moreau et al., 2009). Hence, as suggested by Jonas et al. (1997), any new information such as the attributes of the contraceptive methods and the threat of unwanted pregnancy or abortions may not be processed systematically by such individuals and it may lead to greater attitude-behavior inconsistency. Hence, consumers with high ambivalence are likely to be affected to a lesser extent by their attitudes, intercourse frequency and satisfaction, compared to those with less ambivalent attitudes. Based on this reasoning, we hypothesize that consumer ambivalence not only has a direct negative effect on contraceptive usage but it may also weaken the influence of attitude towards contraception, satisfaction with the most familiar contraceptive method, and intercourse frequency on usage and intentions, as hypothesized below:

H7: Consumer ambivalence toward contraception negatively moderates the effect of attitude toward contraception on contraceptive usage and behavioral intentions.

H8: Consumer ambivalence toward contraception negatively moderates the effect of satisfaction with the most familiar contraceptive method on contraceptive usage and behavioral intentions. 


\section{H9: Consumer ambivalence toward contraception negatively moderates the effect of intercourse frequency on contraceptive usage and behavioral intentions.}

Figure 1 shows all these hypotheses graphically.

$<$ Insert Figure 1 about here $>$

\section{METHODOLOGY}

\section{Sample and Procedure}

We used a team of bilingual female market surveyors provided by a professional market research agency to approach about 2000 females in the 15-44 years age-group in two major public hospitals and six randomly selected private clinics (three General physicians and Gynecologists each) located across Singapore during opening hours (usually 9:00am-5:00pm) over a three month period. The survey team was briefed and trained by the researchers to familiarize them with the survey questionnaire and its administration procedure as well as the need to protect the anonymity and confidentiality of the participants.

The surveyors approached the potential respondents after they had they finished their consultation with the doctor and asked them if they would like to participate in an anonymous survey about female healthcare. Those who agreed to participate were taken to a separate cubicle to complete the questionnaire on their own while the surveyor was available nearby to clarify any queries or to translate specific terms from English to the native language of the participant (e.g., Chinese, Malay or Tamil). No personal information (e.g., name or address) was collected from the participants and no incentive was given to them. The final sample consists of 588 sexually active females and shows a good response rate (about 29\%).

We refer to our approach as 'Clinic-intercept' because it is similar to the 'Mall-intercept' approach commonly used by marketing researchers to approach and recruit shoppers for their 
studies (Bush and Hair, 1985; Rice and Hancock, 2005). We chose this method because based on our findings in the exploratory phase of our research; contraception is a sensitive subject to be discussed in a public place like a shopping mall. Accordingly the clinical setting would be the most appropriate place to conduct the research, not only to ensure complete anonymity and confidentiality of the female participants but also to make them feel more comfortable and at ease in answering questions on this sensitive subject.

\section{Questionnaire and Measures}

A structured questionnaire was used to measure all the variables. Attitude toward contraception (ATT) was measured with an eight-item scale (Brückner et al., 2004) and satisfaction with the most familiar contraceptive method (SAT) with a three-item scale (Layte et al., 2007), both using seven-point Semantic Differential scales. Behavioral intentions (BI) were measured with a three-item scale using a five-point Likert scale $(1=$ strongly disagree to $5=$ strongly agree). Consumer ambivalence towards contraception was operationalized by first measuring positive (POS) and negative (NEG) perceptions about contraception separately and then using Griffin's formula to calculate the ambivalence score (Thompson et al., 1995). Finally, intercourse frequency (ICF), contraceptive usage (USE), demographics (age, education, ethnicity, income, marital status, number of children and occupation) and socio-normative variables (perceived influence of male partner, family and doctors) were recorded.

\section{Measurement Model}

Confirmatory factor analysis was used to validate the measurement model and it shows a good fit $\left(\chi^{2}=430.47, d f=233, p<.001, \chi^{2} / d f=1.85 ; \mathrm{RMSEA}=.042, \mathrm{SRMR}=.058, \mathrm{CFI}=.97\right.$, $\mathrm{NFI}=.95)$ with all the fit-indices better than the recommended cut-off values $($ RMSEA $<.06$, 
SRMR $<.08, \mathrm{CFI}>.95)$ by Hu and Bentler $(1999)$ and $\left(1<\chi^{2} / d f<3\right)$ by Wheaton et al. (1977). All factor loadings are large $(>.70)$ with high t-values $(9.84-19.38)$ and no significant crossfactor loadings. Table 1 shows psychometric properties and descriptives for all the scale items.

$<$ Insert Table 1 about here $>$

All the parameter estimates $(\lambda)$ are significantly different from zero at the $5 \%$ level, showing convergent validity; and none of the confidence intervals of the correlation coefficients for each pair of scales ( $\Phi$ estimates) includes 1.0, which shows discriminant validity (Anderson and Gerbing, 1988). We also constrained the estimated correlation parameters among the nine factors to 1.0 and then performed a test for the difference between $\chi^{2}$ values for the constrained and unconstrained models. The $\chi^{2}$ value for the constrained model $(941.88, d f=254)$ is significantly higher $\left(\Delta \chi^{2}=352.12, \Delta d f=21, \mathrm{p}<.001\right)$ than the unconstrained model, showing that the factors are not perfectly correlated (Anderson and Gerbing, 1988). All the construct reliabilities ( 0.80 to 0.84$)$ are much higher than .60 , showing that all the scales are reliable (Bagozzi and Yi, 1988). Finally, the average variance extracted for each construct (.57 to .65) is higher than .50 as well as the square of its correlation with each of the other constructs, which provide further evidence of convergent validity (Fornell and Larcker, 1981). Table 2 shows the correlations table with composite reliability and average variance extracted for all the scales.

$$
<\text { Take in Table } 2 \text { about here }>
$$

\section{Control Variables}

Age, ethnicity and marital status have a significant influence as shown in Table 3. Older consumers show a more favorable attitude toward contraception and higher satisfaction with their most familiar contraceptive method, contraceptive usage and intentions, but the younger consumers show higher intercourse frequency and ambivalence. Ethnic Chinese consumers show 
more favorable attitudes and satisfaction and higher level of contraceptive usage and intentions, whereas consumers with other ethnicities show greater ambivalence and intercourse frequency. Finally, married participants show more favorable attitudes and higher satisfaction, intercourse frequency, usage and behavioral intentions; whereas singles show greater ambivalence.

$<$ Insert Table 3 about here $>$

Among the other control variables, socio-normative factors such as perceived influence of male partner had a significant positive effect on attitude towards contraception, satisfaction with the most familiar method, intercourse frequency and contraceptive usage. In contrast, the perceived influence of doctors had a significant positive effect only on attitude and usage; whereas perceived influence of family did not affect any of these variables. None of these socionormative variables had any effect on ambivalence about contraception and all the other significant effects are also rather small. Finally, none of the control variables interacts with the other independent variables hence they are not discussed any further in this paper.

\section{Hypotheses Testing and Results}

We used moderated multiple regression analysis to test all the hypotheses (Baron and Kenny, 1986). We first calculated the ambivalence index using the Griffin formula (Thompson et al., 1995) as follows: Ambivalence Index $=($ Positive + Negative $) / 2-\mid$ Positive - Negative $\mid$. In this formula, the terms Positive and Negative represent the average scores on the items measuring positive and negative perceptions about contraception. The values of the ambivalence index ranged between -1.00 to +4.50 . Next, we calculated the average scores for all the other variables, as shown in Table 2. We then mean-centered all the scores and entered them into a regression model. We found a good fit (adj. $\left.\mathrm{R}^{2}=.36\right)$ for this model and all the regression coefficients were significant at $\mathrm{p}<.01$ level. Next, we created interaction terms by multiplying 
the mean-centered scores for ATT, SAT and ICF with AMB to test the moderating effects of AMB, and entered them into the regression model. The model fit improved significantly (adj. $\mathrm{R}^{2}$ $\left.=.44 ; \Delta \mathrm{R}^{2}=.08, \mathrm{p}<.01\right)$ with most regression coefficients significant at $\mathrm{p}<.05$ level or better. Table 4 shows all the hypotheses and summarizes all the results.

$<$ Insert Table 4 about here $>$

Attitude toward contraception has a positive effect on contraceptive usage $(\beta=.24, \mathrm{p}<$ $.001)$ and behavioral intentions $(\beta=.29, \mathrm{p}<.001)$, supporting H1; satisfaction with the most familiar contraceptive method has a positive effect on both usage $(\beta=.16, p<.01)$ and intentions $(\beta=.26, \mathrm{p}<.001)$, supporting H2. Intercourse frequency has no significant effect on usage $(\beta=.04, p>.50)$ but it has a positive effect on intentions $(\beta=.09, \mathrm{p}<.05)$, thus only partly supporting H3. However, the interaction between attitude and intercourse frequency for usage $(\beta=.13, \mathrm{p}<.01)$ and intentions $(\beta=.10, \mathrm{p}<.05)$ as well as between satisfaction and intercourse frequency for usage $(\beta=.15, \mathrm{p}<.01)$ and intentions $(\beta=.12, \mathrm{p}<.01)$ are all significant, supporting H4 and H5.

Ambivalence toward contraception has a negative effect on usage $(\beta=-.10, p<.05)$ and intentions $(\beta=-.08, \mathrm{p}<.05)$, hence H6 is also supported. The interaction between attitude and ambivalence is significant for intention $(\beta=-.13, p<.01)$ but not for usage $(\beta=-.06, p>.20)$, hence $\mathrm{H} 7$ is only partly supported. In contrast, the interaction between satisfaction and ambivalence is significant for usage $(\beta=-.11, \mathrm{p}<.01)$ but not for intentions $(\beta=-.07, \mathrm{p}>.10)$, hence H8 is also only partly supported. Finally, the interaction between intercourse frequency and ambivalence is significant for both usage $(\beta=-.13, \mathrm{p}<.01)$ and intentions $(\beta=-.09, \mathrm{p}<$ .05), providing support to H9. Overall, six out of nine hypotheses are fully supported and the 
other three are partly supported with either the usage or the intentions being significantly affected. Next, we discuss these results, their conceptual contribution and practical implications.

\section{DISCUSSION}

In this research, we explore consumer ambivalence towards contraception as a possible reason for low and inconsistent contraception usage, an important issue for the health and wellbeing of female consumers around the world (Cleland et al., 2012; Darroch and Singh, 2013). It is believed that this study is among the first to provide evidence that female consumers exhibit ambivalence towards contraception. Specifically, we found that female consumers in Singapore think that contraception is convenient, affordable, reliable and easily available; however, they are also concerned about the negative short-term and long-term effects of contraceptive and many of them consider contraception being embarrassing or not congruent with their religious values.

We also found that ethnic Chinese female consumers in Singapore report higher levels of contraceptive usage and intentions, possibly due to their higher income and education levels compared to other ethnic groups in Singapore. Moreover, younger, single and non-Chinese female consumers have higher levels of consumer ambivalence towards contraception compared to their older, married and Chinese counterparts. From these findings it is seems that several demographics and cultural factors may have a significant effect on the decision to use contraception and the choice of contraceptive method for female consumers.

Attitude toward contraception and satisfaction (H1-H2): We found that attitudes toward contraception and satisfaction with the most familiar contraceptive method have a positive effect on contraceptive usage as well as behavioral intentions such as willingness to try contraception, seek more information about it and continue its usage. These results validate findings reported in prior research showing satisfaction with contraceptive methods as one of the 
most important determinant of contraception usage (e.g., Frost and Darroch, 2008; Hormes and Rozin, 2011; Moreau et al., 2009; Nowlis et al., 2002).

Intercourse frequency (H3-H5): As expected, intercourse frequency has a significant direct effect on the intentions although we did not find any evidence of its impact on past contraceptive usage. However, we found that it does moderate the influence of attitudes and satisfaction on both usage and intentions. These findings show that female consumers with higher frequency of intercourse may not have used contraception in the past but they seem quite keen to use it in future. Moreover, their attitudes towards contraception and satisfaction with their most familiar contraceptive method are likely to have a stronger impact on their past usage as well intentions to use contraception in future, possibly in order to avoid the inconvenience of unwanted pregnancies and abortion.

Consumer ambivalence about contraception (H6-H9): We found that consumer ambivalence has a negative effect on contraceptive usage and behavioral intentions, and it also moderates the effect of intercourse frequency on both usage and intentions. However, we only found mixed evidence about its moderating impact on the influence of attitude and satisfaction on usage and intentions. Overall, these findings show that consumers with ambivalent attitudes about contraception are more likely to use contraceptives if their intercourse frequency is high. This may be because using contraceptives may help them avoid the uncertainty and minimize the fear of unwanted pregnancy due to their higher level of sexual activity. Hence, healthcare and welfare agencies may focus their efforts on the female consumers with lower intercourse frequency to improve their contraceptive usage rates as well.

The mixed support to some of the hypotheses is possibly due to the inconsistency between the reported actual usage and behavioral intentions, which is quite common in cross- 
sectional studies such as ours in consumer behavior, ambivalence or even contraception. For example, even Olsen et al. (2005) found a significant direct effect of ambivalence on satisfaction but no moderating effect on the satisfaction-loyalty link. Hence, it would be useful to follow-up our study with those using a longitudinal design, in improve the consistency between actual usage and behavioral intentions.

Overall, our findings extend the prior research on contraception as well as consumer ambivalence. We introduce the concept of consumer ambivalence about contraception to the field of contraception research, and we extend the research on consumer ambivalence by testing its impact in an important context related to female health and well-being. We also suggest that consumer involvement (as reflected by intercourse frequency) may be an important moderator in the contraceptive usage behavior and highlight its importance in ambivalence literature despite prior mixed findings (Olsen et al., 2005; Tuu and Olsen, 2010).

Interestingly, we also found that the doctors' opinions had a significant positive effect on attitude towards contraception and contraceptive usage but family members did not have any such effect. This finding suggests that with increasing education and income levels coupled with rise in the number of nuclear families and access to world-class healthcare facilities, the new generation of female consumers in Singapore are more likely to rely on experts (e.g., doctors and other healthcare professionals) unlike their earlier generations who seemed to rely more on the opinions and influence of their family members (e.g., spouse, mothers or mothers-in-law).

Besides validating similar results reported in prior research about the influence of age, marital status and ethnicity on ambivalence (e.g., Ng et al., 2011; Park, 2005), these findings also highlight the need to understand the individual differences in consumer ambivalence among various consumer segments in order to address its impact on consumer behavior and intentions. 
For example, health and welfare organizations can specifically target their communication campaigns at these groups of female consumers (younger, single and non-Chinese) to try and reduce their ambivalence about contraception and to improve their contraception usage.

Our research also has important practical and managerial implications. First, by showing the influence of various factors on contraceptive usage, this study may help make female consumers, their male partners and family members aware of the reasons for low or inconsistent contraception usage. We hope it would help them overcome these influences and improve their contraceptive usage levels. These findings may also help those involved in managing the reproductive health and well-being of women around the world (e.g., healthcare professionals, social workers, welfare organizations) develop more focused consumer education programs and communication campaigns to target the most appropriate consumer segments with the right message, in order to reduce their ambivalence and improve their contraception usage rates.

Specifically, contraceptive manufacturers can use our findings to target the appropriate segments (either low or high in ambivalence) with the most appropriate messages. For example, the messages for high ambivalence consumers would need to reduce their ambivalence while the thrust of the message for low ambivalence consumers would be on reinforcement of the utility of contraception. The same implications hold true for policy makers. Overall, our research can be used to enhance quality of female consumers' health and well-being by reducing their ambivalence, enhancing contraception usage and prevent unwanted pregnancies.

Our research shows that it is a combination of attitudinal (attitude toward contraception and ambivalence), experiential (satisfaction with the most familiar contraceptive method) and behavioral (intercourse frequency) variables that influence contraceptive usage and intentions. We also show that consumer ambivalence about contraception as well as intercourse frequency 
play indirect roles in this process. Hence, future consumer education efforts should work on multiple fronts - educate female consumers about the choices and benefits of contraceptive methods available to them (to improve their attitudes toward contraception); ensure their correct usage through consumer education (to improve compliance and satisfaction); and to use suitable case studies and examples (to make the consumers aware about their ambivalent attitudes and help them reduce their ambivalence).

According to the Elaboration-Likelihood Model, there are two routes to persuasion, the peripheral route and central route (Petty and Cacioppo, 1986). The less educated and/or younger consumers with lower levels of sexual activities may use the peripheral route to process information regarding contraceptive methods due to their lower involvement with contraception; hence celebrity endorsements can be used to promote the positive aspects of contraceptive usage and to make their attitudes towards contraception more positive by reducing ambivalence. In contrast, for older and/or more educated consumers with higher frequency of sexual activity, a relatively more central route may be more likely to work, by sharing more detailed information with education material such as brochures, displays and video clips.

In general, ambivalence is determined by extreme positions; that is, a stimulus that has both negative and positive attributes leads to more ambivalence vis-à-vis another one that is average on all attributes (Nowlis et al., 2002). Therefore, the less extreme attributes of contraceptives can be highlighted to reduce ambivalence toward them and to improve their acceptance and usage. For example, it could be shown that condoms have major positive attributes (e.g., protection from sexually transmitted diseases, easy availability, convenience, and no side effects) and only minor negatives (e.g., little impact on sexual pleasure and no major religious opposition). This should help reduce ambivalence towards condom usage. 
For consumers with low sexual activity, contraception usage could be low due to their lower involvement. Their involvement may be increased by appropriate communication tactics such as moderate fear appeals (e.g. danger of getting AIDS may be avoided by using condoms). This could help in improving their contraceptive usage. Similarly, we found that satisfaction with the most familiar contraceptive method also drives contraceptive usage. Hence, marketers should try to improve the quality of their contraceptive products to enhance customer satisfaction.

\section{LIMITATIONS AND FUTURE RESEARCH}

This paper has a few limitations that future research may address. First, it focuses on female consumers' ambivalence about contraception and its impact on their contraceptive usage and intentions. Future research could explore ambivalence towards contraception among male consumers and compare the differences in the influence of male and female partners on the use of contraception and the choice of contraceptive method. Future research may also explore the possibility that consumers make their contraceptive choices in a two-stage decision-making process - (a) the decision to use contraception, and (b) the choice of a specific contraception method. Hence, it would be useful to examine different levels of consumer ambivalence (about contraception and specific contraceptive methods) and their impact on the consumer decisionmaking process. Moreover, this paper focuses on the impact of consumer ambivalence on the attitude-behavior link based on past research. However, some researchers recommend looking beyond attitudinal ambivalence and using other constructs such as belief homogeneity (Armitage, 2003) or culture (Ng et al., 2011). We also found some significant differences based on the ethnicity of the participants in our study. Hence, a similar study conducted with a broader sample of various ethnicities in different regions of the world would help us understand the important role of culture on consumer ambivalence towards contraception. 


\section{REFERENCES}

Acharya, D.R., Bhattarai, R., Poobalan, A., van Teijlingen, E.R. and Chapman, G. (2010), "Factors associated with teenage pregnancy in South Asia: a systematic review", Health Sciences Journal, Vol. 4, No. 1, pp. 3-14.

Anderson, J.C. and Gerbing, D.W. (1988), "Structural equation modeling in practice: A review and recommended two step approach", Psychological Bulletin, Vol. 103, No. 3, pp. 411423.

Armitage, C.J. (2003), "Beyond attitudinal ambivalence: effects of belief homogeneity on attitude-intention-behaviour relations", European Journal of Social Psychology, Vol. 33, No. 4, pp. 551-563.

Armitage, C.J. and Conner, M. (2000), "Attitudinal Ambivalence: A test of three key hypotheses", Personality and Social Psychology Bulletin, Vol. 26, No. 11, pp. 14211432.

Bagozzi, R.P. and Yi, Y. (1988), "On the evaluation of structural equation models", Journal of the Academy of Marketing Sciences, Vol. 16, No. 1, pp. 74- 84.

Bargh, J.A., Chaiken, S., Govender, R. and Pratto, F. (1992), "The generality of the automatic attitude activation effect", Journal of Personality and Social Psychology, Vol. 62, No. 6, pp. 893-912.

Baron, R.M. and Kenny, D.A. (1986), "The Moderator-Mediator variable in social psychological research: Conceptual, strategic and statistical considerations", Journal of Personality and Social Psychology, Vol. 51, No. 6, pp. 1173-1182.

Breckler, S.J. (1994), "A comparison of numerical indexes for measuring attitude ambivalence", Education and Psychological Measurement, Vol. 54, No. 2, pp. 350-365.

Brooks, M.E., Highhouse, S., Russell, S.S. and Mohr, D.C. (2003), "Familiarity, Ambivalence, and Firm Reputation: Is Corporate Fame a Double-Edged Sword?", Journal of Applied Psychology, Vol. 88, No. 5, pp. 904-914.

Brückner, H., Martin, A. and Bearman, P.S. (2004), "Ambivalence and Pregnancy : Adolescents' Attitudes, Contraceptive Use and Pregnancy", Perspectives on Sexual \& Reproductive Health, Vol. 36, No. 6, pp. 248-257.

Brunner Huber, L.R. and Ersek, J.L. (2011), "Perceptions of contraceptive responsibility among female college students: an exploratory study", Annals of Epidemiology, Vol. 21, No. 3, pp. 197-203.

Bush, A. J., \& Hair, Joseph F., Jr. (1985). "An assessment of the mall intercept as a data collection method", Journal of Marketing Research, Vol. 22, No. 2, pp. 158-167. 
Cacioppo, J.T., Gardner, W.L. and Berntson, G.G. (1997), "Beyond bipolar conceptualizations and measures: The case of attitudes and evaluative space", Personality and Social Psychology Review, Vol. 1, No. 1, pp. 3-25.

Carr, B., Gates, M.F., Mitchell, A. and Shah, R. (2012), "Giving women the power to plan their families", The Lancet, Vol. 380, No. 9837, pp. 80-82.

Cavazza, N. and Butera, F. (2008), "Bending without breaking: examining the role of attitudinal ambivalence in resisting persuasive communication", European Journal of Social Psychology, Vol. 38, No. 1, pp. 1-15.

CDCP (2012), "Prepregnancy Contraceptive Use Among Teens with Unintended Pregnancies Resulting in Live Births - Pregnancy Risk Assessment Monitoring System (PRAMS), 2004-2008", Morbidity and Mortality Weekly Report. Center for Disease Control and Prevention. pp. 25-29.

Chaiken, S., Liberman, A. and Eagly, A.H. (1989), "Heuristic and systematic information processing within and beyond the persuasion context", in Uleman, J.S. \& Bargh, J.A. (Eds.) Unintended thought. New York, NY, Guilford. pp. 212-252.

Chang, C. (2011), "Feeling ambivalent about going green: implications for green advertising processing", Journal of Advertising, Vol. 40, No. 4, pp. 19-32.

Chen, C.-F. and Tsai, M.-H. (2008), "Perceived value, satisfaction, and loyalty of TV travel product shopping: Involvement as a moderator", Tourism Management, Vol. 29, No. 6, pp. 1166-1171.

Clarkson, J.J., Tormala, Z.L. and Rucker, D.D. (2008), "A new look at the consequences of attitude certainty: The amplification hypothesis", Journal of Personality and Social Psychology, Vol. 95, No. 4, pp. 810-825.

Cleland, J., Conde-Agudelo, A., Peterson, H., Ross, J. and Tsui, A. (2012), "Contraception and health", The Lancet, Vol. 380, No. 9837, pp. 149-156.

Conner, M., Povey, R., Sparks, P., James, R. and Shepherd, R. (2003), "Moderating role of attitudinal ambivalence within the theory of planned behaviour", British Journal of Social Psychology, Vol. 42, No. 1, pp. 75-94.

Conner, M., Sparks, P., Povey, R., James, R., Shepherd, R. and Armitage, C.J. (2002), "Moderator effects of attitudinal ambivalence on attitude-behaviour relationships", European Journal of Social Psychology, Vol. 32, No. 5, pp. 705-718.

Cox, S., Posner, S.F. and Sangi-Haghpeykar, H. (2010), "Who's responsible? Correlates of partner involvement in contraceptive decision making", Womens Health Issues, Vol. 20, No. 4, pp. 254-259. 
Dahl, D.W., Darke, P.R., Gorn, G.J. and Weinberg, C.B. (2005), "Promiscuous or Confident? Attitudinal Ambivalence Toward Condom Purchase", Journal of Applied Social Psychology, Vol. 35, No. 4, pp. 869-887.

Darroch, J.E., Sedgh, G. and Ball, H. (2011), "Contraceptive Technologies: Responding to Women's Needs". New York, Guttmacher Institute.

Darroch, J.E. and Singh, S. (2013), "Trends in contraceptive need and use in developing countries in 2003, 2008, and 2012: an analysis of national surveys", Lancet, Vol. 381, No. 9879, pp. 1756-1762.

Eagly, A.H. and Chaiken, S. (1993), The Psychology of Attitudes, Fort Worth, TX, Harcourt Brace.

Erramilli, M.K., Sharma, P., Chung, C.M.Y. and Sivakumaran, B. (2005), "Health Literacy, Sex Education and Contraception: The Singapore Experience", Studies in Communication Sciences, Vol. 5, No. 2, pp. 147-158.

Ersek, J.L., Huber, L.R.B., Thompson, M.E. and Warren-Findlow, J. (2011), "Satisfaction and Discontinuation of Contraception by Contraceptive Method Among University Women", Maternal and Child Health Journal, Vol. 15, No. 4, pp. 497-506.

Festinger, L. (1957), A theory of cognitive dissonance, Stanford, CA, Stanford University Press.

Fisher, W.A., Singh, S.S., Shuper, P.A., Carey, M., Otchet, F., MacLean-Brine, D., Dal Bello, D. and Gunter, J. (2005), "Characteristics of women undergoing repeat induced abortion", Canadian Medical Association Journal, Vol. 172, No. 5, pp. 637-641.

Fornell, C. and Larcker, D.F. (1981), "Evaluating Structural Equation Models with Unobservable Variables and Measurement Error", Journal of Marketing Research, Vol. 18, No. 3, pp. $382-388$

Frost, J.J. and Darroch, J.E. (2008), "Factors Associated with Contraceptive Choice and Inconsistent Method Use, United States, 2004", Perspectives on Sexual \& Reproductive Health, Vol. 40, No. 2, pp. 94-104.

Hass, R.G., Katz, I., Rizzo, N., Bailey, J. and Moore, L. (1992), "When racial ambivalence evokes negative affect, using a disguised measure", Personality and Social Psychology Bulletin, Vol. 18, No. 6, pp. 786-797.

Higgins, J.A. and Cooper, A.D. (2012), "Dual use of condoms and contraceptives in the USA", Sex Health, Vol. 9, No. 1, pp. 73-80.

Hong, J. and Lee, A.Y. (2010), "Feeling Mixed but Not Torn: The Moderating Role of Construal Level in Mixed Emotions Appeals", Journal of Consumer Research, Vol. 37, No. pp. 456-472. 
Hormes, J.M. and Rozin, P. (2011), "The temporal dynamics of ambivalence: Changes in positive and negative affect in relation to consumption of an "emotionally charged" food", Eating Behaviors, Vol. 12, No. 3, pp. 219-221.

Hu, L.-t. and Bentler, P.M. (1999), "Cutoff criteria for fit indexes in covariance structure analysis: conventional criteria versus new alternatives", Structural Equation Modeling, Vol. 6, No. 1, pp. 1-55.

Jewell, R.D. (2003), "The Effects of Deadline Pressure on Attitudinal Ambivalence", Marketing Letters, Vol. 14, No. 2, pp. 83-95.

Jonas, K., Diehl, M. and Broemer, P. (1997), "Effects of Attitudinal Ambivalence on Information Processing and Attitude-Intention Consistency", Journal of Experimental Social Psychology, Vol. 33, No. 2, pp. 190-210.

Kaplan, K.J. (1972), "On the ambivalence-indifference problem in attitude theory and measurement: A suggested modification of the semantic differential technique", Psychological Review, Vol. 77, No. 5, pp. 361-372.

Kearney, M.S. and Levine, P.B. (2012), "Why is the Teen Birth Rate in the United States so High and Why Does it Matter?". Cambridge, MA, National Bureau of Economic Research.

Kraus, S.J. (1995), "Attitudes and the prediction of behavior: A meta-analysis of the empirical literature", Personality and Social Psychology Bulletin, Vol. 21, No. 1, pp. 58-75.

Layte, R., McGee, H., Rundle, K. and Leigh, C. (2007), "Does ambivalence about becoming pregnant explain social class differentials in use of contraception?", European Journal of Public Health, Vol. 17, No. 5, pp. 477-482.

Lipkus, I.M., Feaganes, J.R., Green, J.D. and Sedikides, C. (2001), "The Relationship Between Attitudinal Ambivalence and Desire to Quit Smoking Among College Smokers", Journal of Applied Social Psychology, Vol. 31, No. 1, pp. 113-133.

Maio, G.R., Bell, D.W. and Esses, V.M. (1996), "Ambivalence and Persuasion: The Processing of Messages about Immigrant Groups", Journal of Experimental Social Psychology, Vol. 32, No. 6, pp. 513-536.

Martinez, G., Copen, C.E. and Abma, J.C. (2011), "Teenagers in the United States: sexual activity, contraceptive use, and childbearing, 2006-2010 national survey of family growth", Vital Health Statistics. Hyattsville, MD, Division of Vital Statistics, Centers for Diseases Control and Prevention, National Center for Health Statistics. pp. 1-35.

McKay, A. and Barrett, M. (2010), "Trends in teen pregnancy rates from 1996-2006: a comparison of Canada, Sweden, U.S.A., and England/Wales", The Canadian Journal of Human Sexuality, Vol. 19, No. 1-2, pp. 43-52. 
Moore, M. (1980), "Validation of attitude toward any practice scale through the use of ambivalence as a moderator variable", Educational and Psychological Measurement, Vol. 40, No. 1, pp. 205-208.

Moreau, C., Bouyer, J., Bajos, N., Rodriguez, G. and Trussell, J. (2009), "Frequency of discontinuation of contraceptive use: results from a French population-based cohort", Human Reproduction, Vol. 24, No. 6, pp. 1387-1392.

Newby-Clark, I.R., McGregor, I. and Zanna, M.P. (2002), "Thinking and Caring About Cognitive Inconsistency: When and for Whom Does Attitudinal Ambivalence Feel Uncomfortable?", Journal of Personality and Social Psychology, Vol. 82, No. 2, pp. 157166.

Ng, A.H., Hynie, M. and MacDonald, T.K. (2012), "Culture Moderates the Pliability of Ambivalent Attitudes", Journal of Cross-Cultural Psychology, Vol. 43, No. 8, pp. 13131324.

Nowlis, S.M., Kahn, B.E. and Dhar, R. (2002), "Coping with ambivalence: The effect of removing a neutral opinion on consume", Journal of Consumer Research, Vol. 29, No. 3, pp. 319-334.

Oakeley, P. (2004), "Choices of contraception", Current Obstetrics \& Gynaecology, Vol. 14, No. 1, pp. 68-71.

Oddens, B.J. (1999), "Women's satisfaction with birth control: a population survey of physical and psychological effects of oral contraceptives, intrauterine devices, condoms, natural family planning, and sterilization among 1466 women", Contraception, Vol. 59, No. 5, pp. 277-286.

Olsen, S.O. (2007), "Repurchase loyalty: The role of involvement and satisfaction", Psychology and Marketing, Vol. 24, No. 4, pp. 315-341.

Olsen, S.O., Prebensen, N. and Larsen, T.A. (2009), "Including ambivalence as a basis for benefit segmentation: A study of convenience food in Norway", European Journal of Marketing, Vol. 43, No. 5/6, pp. 762-783.

Olsen, S.O., Wilcox, J. and Olsson, U. (2005), "Consequences of Ambivalence on Satisfaction and Loyalty", Psychology \& Marketing, Vol. 22, No. 3, pp. 247-269.

Otnes, C., Lowrey, T.M. and Shrum, L.J. (1997), "Toward an understanding of consumer ambivalence", Journal of Consumer Research, Vol. 24, No. 1, pp. 80-93.

Park, K. (2005), "Psychological Experience of Attitudinal Ambivalence as a Function of Manipulated Source of Conflict and Individual Difference in Self-Construal", Seoul Journal of Business, Vol. 11, No. 1, pp. 65-76. 
Peipert, J.F., Zhao, Q., Allsworth, J.E., Petrosky, E., Madden, T., Eisenberg, D. and Secura, G. (1998), "Continuation and satisfaction of reversible contraception", Obstetrics \& Gynecology, Vol. 117, No. 5, pp. 1105-1113.

Penz, E. and Hogg, M.K. (2011), "The role of mixed emotions in consumer behaviour; Investigating ambivalence in consumers' experiences of approach-avoidance conflicts in online and offline settings", European Journal of Marketing, Vol. 45, No. 1/2, pp. 104132.

Petty, R.E. and Cacioppo, J.T. (1986), "The elaboration likelihood model of persuasion", Advances in Experimental Social Psychology, Vol. 19, No. 1, pp. 124-205.

Petty, R.E., Cacioppo, J.T. and Schumann, D. (1983), "Central and Peripheral Routes to Advertising Effectiveness: The Moderating Role of Involvement", Journal of Consumer Research, Vol. 10, No. 2, pp. 135-146.

Priester, J.R. and Petty, R.E. (2001), "Extending the Bases of Subjective Attitudinal Ambivalence: Interpersonal and Intrapersonal Antecedents of Evaluative Tension", Journal of Personality and Social Psychology, Vol. 80, No. 1, pp. 19-34.

Priester, J.R., Petty, R.E. and Park, K. (2007), "Whence Univalent Ambivalence? From the Anticipation of Conflicting Reactions", Journal of Consumer Research, Vol. 34, No. 1, pp. 11-21.

Rice, R. and Hancock, L. (2005), "The mall intercept: a social norms marketing research tool", The Report of Social Norms, Vol. 4 No. 7, pp. 4-7.

Riketta, M. (2000), "Discriminative Validation of Numerical Indices of Attitude Ambivalence", Current Research in Social Psychology, Vol. 5, No. 5, pp. 63-83.

Roster, C.A. and Richins, M.L. (2009), "Ambivalence and attitudes in consumer replacement decisions", Journal of Consumer Psychology, Vol. 19, No. 1, pp. 48-61.

Snell, W.E., Jr. and Wooldridge, D.G. (2001), "Sexual awareness: Contraception, sexual behaviors, and sexual attitudes", in W. E. Snell, J. (Ed.) New directions in the psychology of human sexuality: Research and theory. Cape Girardeau, MO, Snell Publications.

Sparks, P., Hedderly, D. and Shepherd, R. (1992), "An investigation into the relationship between perceived control, attitude variability and the consumption of two common foods", European Journal of Social Psychology, Vol. 22, No. 1, pp. 55-71.

Stanger-Hall, K.F. and Hall, D.W. (2011), "Abstinence-Only Education and Teen Pregnancy Rates: Why We Need Comprehensive Sex Education in the U.S.", PLoS ONE, Vol. 6, No. 10, pp. 1-11 (e24658).

Thompson, M.M. and Zanna, M.P. (1995), "The conflicted individual: personality-based and domain-specific antecedents of ambivalent social attitudes", Journal of Personality, Vol. 63, No. 2, pp. 259-288. 
Thompson, M.M., Zanna, M.P. and Griffin, D.W. (1995), "Let's not be indifferent about (attitudinal) ambivalence", in Petty, R.E. \& Krosnick, J.A. (Eds.) Attitude strength: Antecedents and consequences. Mahwah, NJ, Lawrence Erlbaum. pp. 361-386.

Tormala, Z.L. and DeSensi, V.L. (2008), "The Perceived Informational Basis of Attitudes: Implications for Subjective Ambivalence", Personality and Social Psychology Bulletin, Vol. 34, No. 2, pp. 275-287.

Tourangeau, R., Rasinski, K.A., Bradburn, N. and D'Andrade, R. (1989), "Carryover Effects in Attitude Surveys", Public Opinion Quarterly, Vol. 53, No. 4, pp. 495-524.

Townsend, J.W., Sitruk-Ware, R., Williams, K., Askew, I. and Brill, K. (2011), "New strategies for providing hormonal contraception in developing countries", Contraception, Vol. 83, No. 5, pp. 405-409.

Tuu, H.H. and Olsen, S.O. (2010), "Ambivalence and involvement in the satisfaction-repurchase loyalty relationship", Australasian Marketing Journal (AMJ), Vol. 18, No. 3, pp. 151158.

Ursavas, B. and Hesapci-Sanaktekin, O. (2013), "What happens when you're lost between happiness and sadness?: Effects on consumers' cognitive responses", Journal of Business Research, Vol. 66, No. 7, pp. 933-940.

Wheaton, B., Muthen, B., Alwin, D.F. and Summers, G.F. (1977), "Assessing reliability and stability in panel models", in R., H.D. (Ed.) Sociological methodology. San Francisco, Jossey-Bass. pp. 84-136.

Yurdakul, M. and Vural, G. (2002), "Reasons for using traditional methods and role of nurses in family planning", Contraception, Vol. 65, No. 5, pp. 347-350.

Zabin, L.S. (1999), "Ambivalent Feelings About Parenthood May Lead to Inconsistent Contraceptive Use and Pregnancy", Family Planning Perspectives, Vol. 31, No. 5, pp. $250-251$.

Zaichkowsky, J.L. (1985), "Measuring the Involvement Construct", Journal of Consumer Research, Vol. 12, No. 3, pp. 341-352. 
Figure 1 - Conceptual Framework \& Hypotheses

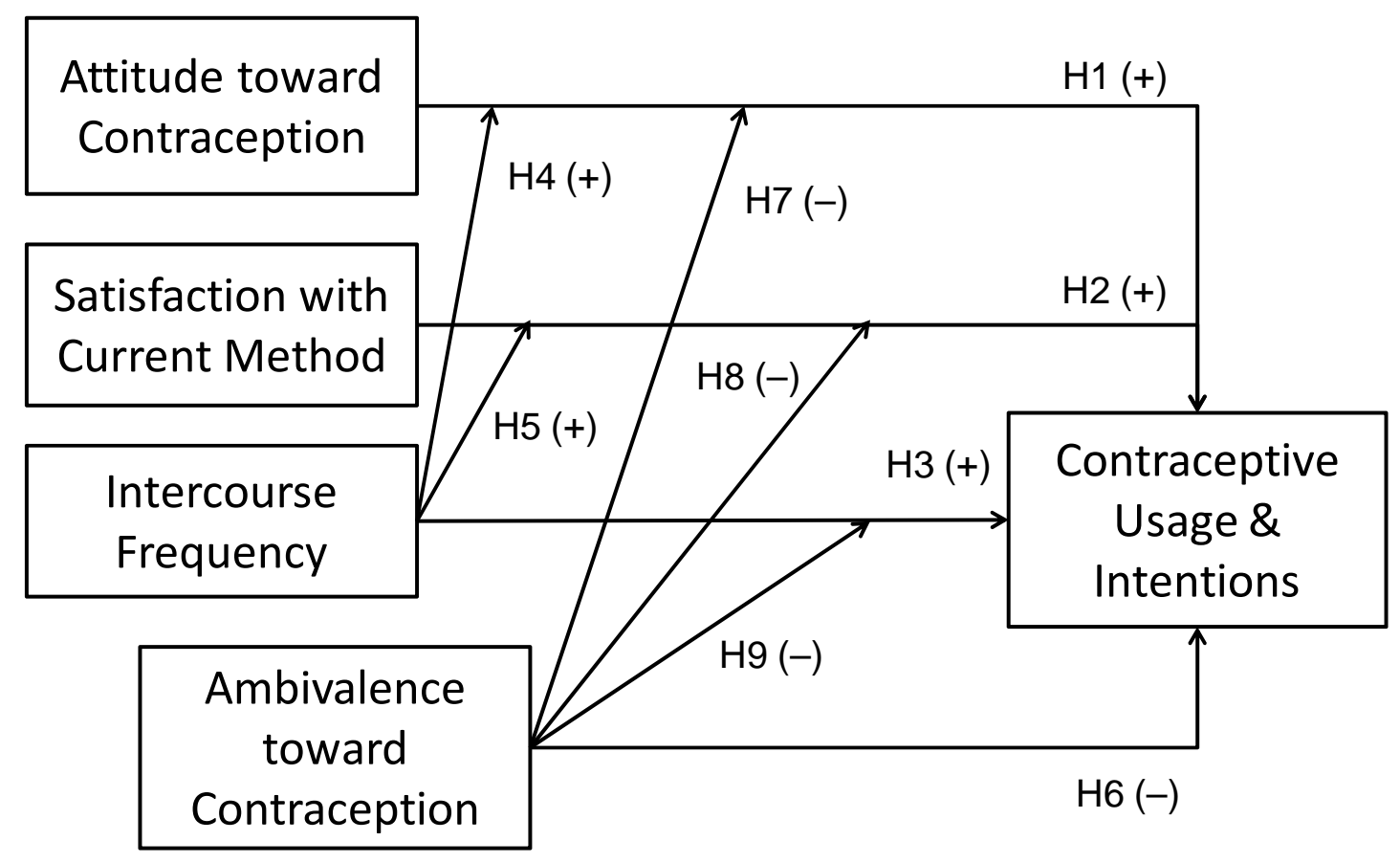


Table 1: Scale Items and Psychometric Properties $(N=588)$

\section{Scale Items \\ Attitude toward contraception}

$\lambda \quad \alpha$

$\boldsymbol{\mu}$

$\boldsymbol{\sigma}$

1. Uncomfortable $1 \quad 2 \quad 3 \quad 4$

2. Unsafe $\quad 1 \quad 2 \quad 3 \quad 4 \quad 50$

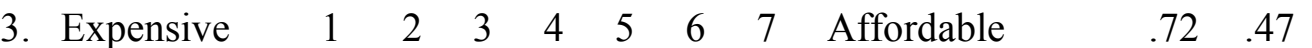

$\begin{array}{lllllllllll}\text { 4. Unnatural } & 1 & 2 & 3 & 4 & 5 & 6 & 7 & \text { Natural } & .78 & .50\end{array}$

$\begin{array}{lllllllllll}\text { 5. Not effective } & 1 & 2 & 3 & 4 & 5 & 6 & 7 & \text { Effective } & .81 & .44\end{array}$

$\begin{array}{lllllllllll}\text { 6. Difficult to use } 1 & 2 & 3 & 4 & 5 & 6 & 7 & \text { Easy to use } & .79 & .45\end{array}$

$\begin{array}{llllllllllll}\text { 7. Embarrassing } & 1 & 2 & 3 & 4 & 5 & 6 & 7 & \text { Not embarrassing } & .74 & .55\end{array}$

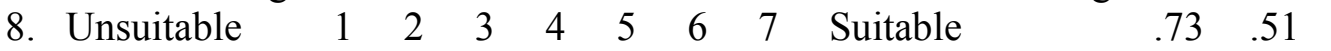

$4.92 \quad 1.30$

$4.55 \quad 1.37$

$4.91 \quad 1.15$

$4.89 \quad 1.37$

$4.98 \quad 1.08$

$4.78 \quad 1.06$

$4.63 \quad 1.20$

$4.58 \quad 1.63$

\section{Satisfaction with the most familiar contraceptive method}

$\begin{array}{lllllllllllll}\text { 1. Dissatisfied } & 1 & 2 & 3 & 4 & 5 & 6 & 7 & \text { Satisfied } & .82 & .65 & 5.14 & 1.11 \\ \text { 2. Unhappy } & 1 & 2 & 3 & 4 & 5 & 6 & 7 & \text { Happy } & .81 & .62 & 4.99 & 1.14 \\ \text { 3. Displeased } & 1 & 2 & 3 & 4 & 5 & 6 & 7 & \text { Pleased } & .78 & .58 & 4.93 & 1.18\end{array}$

\section{Consumer ambivalence toward contraception}

( $\mathrm{P}=$ Positive perceptions; $\mathbf{N}=$ Negative perceptions)

$(1=$ Strongly disagree, $5=$ Strongly agree $)$

1. Convenient $(\mathrm{P})$

$\begin{array}{llll}.77 & .57 & 4.21 & .78\end{array}$

2. Affordable $(\mathrm{P})$

$\begin{array}{llll}.79 & .58 & 4.68 & .86\end{array}$

3. Reliable (P)

4. Easily available (P)

$\begin{array}{llll}.81 & .59 & 4.53 & .94\end{array}$

5. Short-term side effects $(\mathrm{N})$

$\begin{array}{llll}.82 & .62 & 4.34 & .76\end{array}$

6. Long-term bad effects $(\mathrm{N})$

$\begin{array}{llll}.76 & .56 & 2.38 & .93\end{array}$

7. Embarrassing $(\mathrm{N})$

8. Against religion $(\mathrm{N})$

$\begin{array}{llll}.74 & .53 & 2.12 & .89\end{array}$

$\begin{array}{llll}.75 & .54 & 2.09 & .78\end{array}$

$\begin{array}{llll}.78 & .56 & 2.29 & .95\end{array}$

\section{Behavioral intentions toward contraception}

( 1 = Strongly disagree, $5=$ Strongly agree $)$

1. I would like to continue using contraception

$\begin{array}{llll}.78 & .73 & 4.62 & .85\end{array}$

2. I would like to know more about contraception

$\begin{array}{llll}.82 & .66 & 4.81 & .93\end{array}$

3. I would like to use contraception regularly

$\begin{array}{llll}.76 & .71 & 4.52 & .76\end{array}$

Note: $\lambda$ : Factor loadings, $\alpha$ : Corrected Item-to-Total Correlations; $\mu$ : Mean, $\sigma=$ Std. Dev. 
Table 2: Correlations Table $(\mathbf{N}=\mathbf{5 8 8})$

\begin{tabular}{|c|c|c|c|c|c|c|c|c|c|c|c|c|c|}
\hline & Unit & ATT & SAT & ICF & POS & NEG & AMB & USE & INT & MIN & MAX & Mean & SD \\
\hline Attitude (ATT) & $\begin{array}{c}1-7 \\
\text { scale }\end{array}$ & - & - & - & - & - & - & - & - & 3.36 & 7.00 & 4.78 & 1.24 \\
\hline Satisfaction (SAT) & $\begin{array}{c}1-7 \\
\text { scale }\end{array}$ & $.62^{* * *}$ & - & - & - & - & - & - & - & 1.00 & 7.00 & 5.02 & 1.12 \\
\hline $\begin{array}{l}\text { Intercourse } \\
\text { Frequency (ICF) }\end{array}$ & $\begin{array}{l}\text { Times/ } \\
\text { week }\end{array}$ & .08 & .06 & - & - & - & - & - & - & 1 & 4 & 1.98 & .69 \\
\hline Positive items (POS) & $\begin{array}{c}1-5 \\
\text { scale }\end{array}$ & $.45^{* * *}$ & $.30^{* *}$ & .05 & - & - & - & - & - & 1.75 & 5.00 & 4.44 & .77 \\
\hline $\begin{array}{l}\text { Negative items } \\
(\mathrm{NEG})\end{array}$ & $\begin{array}{c}1-5 \\
\text { scale }\end{array}$ & $-.15^{* *}$ & $-.12^{*}$ & $-.17^{* *}$ & $-.19^{* *}$ & - & - & - & - & 1.00 & 5.00 & 2.20 & .85 \\
\hline Ambivalence (AMB) & Index & $-.18^{* *}$ & $-.10^{*}$ & $.14^{* *}$ & $-.27^{* *}$ & $.44^{* * *}$ & - & - & - & -1.00 & 4.50 & 1.32 & .69 \\
\hline Current Usage (USE) & \%age & $.22^{* *}$ & .05 & $.16^{* *}$ & -.05 & $-.14^{* *}$ & $-.10^{*}$ & - & - & 0 & 100 & 0.76 & .18 \\
\hline $\begin{array}{l}\text { Behavioral Intention } \\
\text { (INT) }\end{array}$ & $\begin{array}{c}1-5 \\
\text { scale }\end{array}$ & $.27^{* *}$ & $.16^{* *}$ & $.12^{*}$ & $-.18^{* *}$ & $-.19^{* *}$ & $-.13^{* *}$ & $.35^{* * *}$ & & 1.00 & 5.00 & 4.65 & .85 \\
\hline $\begin{array}{l}\text { Composite } \\
\text { Reliability (CR) }\end{array}$ & - & .82 & .84 & NA & .83 & .80 & NA & NA & .81 & - & - & - & - \\
\hline $\begin{array}{l}\text { Average Variance } \\
\text { Extracted (AVE) }\end{array}$ & - & .58 & .65 & NA & .64 & .57 & NA & NA & .62 & - & - & - & - \\
\hline
\end{tabular}


Table 3: Mean Comparison - Demographics $(\mathrm{N}=\mathbf{5 8 8})$

\begin{tabular}{|c|c|c|c|c|c|c|c|}
\hline \multirow[b]{2}{*}{ Construct } & \multirow[b]{2}{*}{$\begin{array}{r}\text { Overall } \\
(\mathrm{N}=588)\end{array}$} & \multicolumn{2}{|c|}{ Age (Median Split) } & \multicolumn{2}{|c|}{ Ethnicity } & \multicolumn{2}{|c|}{ Marital Status } \\
\hline & & $\begin{array}{l}\leq 34 \text { yrs } \\
(\mathrm{N}=318) \\
\end{array}$ & $\begin{array}{l}>34 \mathrm{yrs} \\
(\mathrm{N}=270) \\
\end{array}$ & $\begin{array}{l}\text { Chinese } \\
(\mathrm{N}=\mathbf{4 5 3}) \\
\end{array}$ & $\begin{array}{c}\begin{array}{c}\text { Others } \\
(\mathrm{N}=135)\end{array} \\
\end{array}$ & $\begin{array}{c}\begin{array}{c}\text { Single } \\
(\mathrm{N}=99)\end{array} \\
\end{array}$ & $\begin{array}{c}\text { Married } \\
(\mathrm{N}=\mathbf{4 8 9}) \\
\end{array}$ \\
\hline Attitude (ATT) & 4.78 & 4.22 & $5.44^{* * *}$ & $4.93^{* * *}$ & 4.28 & 4.42 & $4.85^{* * *}$ \\
\hline Satisfaction (SAT) & 5.02 & 4.37 & $5.79^{* * *}$ & $5.19^{* * *}$ & 4.45 & 4.63 & $5.10^{* * *}$ \\
\hline Intercourse Frequency (ICF) & 1.98 & $2.14^{* *}$ & 1.84 & 1.77 & $2.68^{* * *}$ & 1.28 & $2.12^{* * *}$ \\
\hline Positive perceptions (POS) & 4.44 & 4.09 & $4.85^{* * *}$ & $5.18^{* * *}$ & 4.22 & 3.98 & $4.53^{* *}$ \\
\hline Negative perceptions (NEG) & 2.20 & 2.16 & 2.25 & 1.87 & $3.31^{* * *}$ & $2.73^{* * *}$ & 2.09 \\
\hline Ambivalence (AMB) & 1.32 & $1.48^{* *}$ & 1.13 & 1.05 & $2.23^{* * *}$ & $1.69^{* * *}$ & 1.25 \\
\hline Current Usage (USE) & 0.76 & 0.69 & $0.84^{* * *}$ & $0.79^{* * *}$ & 0.66 & 0.64 & $0.78^{* * *}$ \\
\hline Behavioral Intention (INT) & 4.65 & 4.18 & $5.20^{* * *}$ & $4.97^{* * *}$ & 3.58 & 3.69 & $4.84^{* * *}$ \\
\hline
\end{tabular}

Note: Figures with * show significant difference between the two groups for the respective demographic variable. $* p<.05 ; * * p<.01, * * * p<.001$ 
Table 4 - Hypotheses and Results Summary

\begin{tabular}{|c|c|c|c|c|}
\hline $\mathrm{H} \#$ & Hypotheses & $\beta_{\text {(Usage) }}$ & $\beta_{\text {(Intention) }}$ & Result \\
\hline H1 & $\begin{array}{l}\text { Attitude toward contraception has a positive effect } \\
\text { on contraceptive usage and behavioral intentions. }\end{array}$ & $.24^{* * *}$ & $.29^{* * *}$ & Supported \\
\hline $\mathrm{H} 2$ & $\begin{array}{l}\text { Satisfaction with the most familiar contraceptive } \\
\text { method has a positive effect on contraceptive } \\
\text { usage and behavioral intentions. }\end{array}$ & $.16^{* * *}$ & $.26^{* * *}$ & Supported \\
\hline H3 & $\begin{array}{l}\text { Intercourse frequency has a positive effect on } \\
\text { contraceptive usage and behavioral intentions. }\end{array}$ & $.04^{\mathrm{ns}}$ & $.09^{*}$ & $\begin{array}{c}\text { Partly } \\
\text { Supported }\end{array}$ \\
\hline $\mathrm{H} 4$ & $\begin{array}{l}\text { Intercourse frequency positively moderates the } \\
\text { effect of attitude toward contraception on } \\
\text { contraceptive usage and behavioral intentions. }\end{array}$ & $\begin{array}{l}.13^{* *} \\
\beta_{(\text {Low })}=.13 \\
\beta_{(\text {High })}=.36\end{array}$ & $\begin{array}{l}.10^{*} \\
\beta_{(\text {Low })}=.22 \\
\beta_{(\text {High })}=.33\end{array}$ & Supported \\
\hline H5 & $\begin{array}{l}\text { Intercourse frequency positively moderates the } \\
\text { effect of satisfaction with the most familiar } \\
\text { contraceptive method on contraceptive usage and } \\
\text { behavioral intentions. }\end{array}$ & $\begin{array}{l}.15^{* *} \\
\beta_{(\text {Low })}=.07 \\
\beta_{(\text {High })}=.38\end{array}$ & $\begin{array}{l}.12^{* *} \\
\beta_{(\text {Low })}=.11 \\
\beta_{(\text {High })}=.47\end{array}$ & Supported \\
\hline H6 & $\begin{array}{l}\text { Ambivalence toward contraception has a negative } \\
\text { effect on contraceptive usage and behavioral } \\
\text { intentions. }\end{array}$ & $-.10^{*}$ & $-.08^{*}$ & Supported \\
\hline $\mathrm{H} 7$ & $\begin{array}{l}\text { Ambivalence negatively moderates the effect of } \\
\text { attitude toward contraception on contraceptive } \\
\text { usage and behavioral intentions. }\end{array}$ & $\begin{array}{c}-.06^{\mathrm{ns}} \\
\beta_{(\text {Low })}=.28 \\
\beta_{(\text {High })}=.23\end{array}$ & $\begin{array}{l}-.13^{* *} \\
\beta_{(\text {Low })}=.32 \\
\beta_{(\text {High })}=.14\end{array}$ & $\begin{array}{l}\text { Partly } \\
\text { Supported }\end{array}$ \\
\hline H8 & $\begin{array}{l}\text { Ambivalence negatively moderates the effect of } \\
\text { satisfaction with the most familiar contraceptive } \\
\text { method on contraceptive usage and behavioral } \\
\text { intentions. }\end{array}$ & $\begin{array}{l}-.11^{*} \\
\beta_{(\text {Low })}=.22 \\
\beta_{(\text {High })}=.11\end{array}$ & $\begin{array}{l}-.07^{\mathrm{ns}} \\
\beta_{(\text {Low })}=.29 \\
\beta_{(\text {High })}=.21\end{array}$ & $\begin{array}{l}\text { Partly } \\
\text { Supported }\end{array}$ \\
\hline H9 & $\begin{array}{l}\text { Ambivalence negatively moderates the effect of } \\
\text { intercourse frequency on contraceptive usage and } \\
\text { behavioral intentions. }\end{array}$ & $\begin{array}{c}-.13^{* *} \\
\beta_{(\text {Low })}=.10 \\
\beta_{(\text {High })}=-.08\end{array}$ & $\begin{array}{l}-.09^{*} \\
\beta_{(\text {Low })}=.17 \\
\beta_{(\text {High })}=.02\end{array}$ & Supported \\
\hline
\end{tabular}

Note: $\beta=$ Std Reg. Coeff for the independent variable; $\beta_{(\text {Low })}=$ Std Reg. Coeff for the lower value of moderator; $\beta_{(\mathrm{High})}=$ Std Reg. Coeff for the higher value of moderator $* p<.05, * * p<.01, * * * p<.001, \mathrm{~ns}=$ not significant 